\title{
Concepções e práticas de experimentação nos anos iniciais do ensino fundamental
}

\author{
João Alberto da Silva \\ Julio Cesar Bresolin Marinho \\ Grasilele Ruiz Silva \\ Roberta Chiesa Bartelmebs \\ Universidade Federal do Rio Grande
}

\section{Resumo}

Este estudo caracteriza-se como uma pesquisa qualitativa relacionada a procedimentos escolares e concepções de docentes sobre experimentação, atividade instrumental ou aula prática. Para tanto, realizamos entrevistas com professores atuantes nos anos iniciais do ensino fundamental de escolas públicas do município de Rio Grande/RS, juntamente com observações de suas aulas, a fim de analisarmos a forma pela qual a experimentação é utilizada no processo de ensino e aprendizagem de ciências. Por meio dos dados coletados, percebemos que os tipos de materiais utilizados, o cotidiano dos alunos e a possibilidade de uma construção de aprendizagem são pontos importantes para o professor, ao tratar de atividades práticas em sua aula.

Palavras-chave: Experimentação. Ensino de ciências. Construtivismo. 


\section{Conceptions and practices of experimentation in the first years of elementary school}

This study is the result of qualitative research of school procedures and teachers' conceptions about experimentation, instrumental activity, or practical classes. We have interviewed teachers working in the first years of elementary school in the town of Rio Grande/RS and observed their classes, in order to analyze the way in which experimentation is used in the science teaching and learning process. Through the collected data we perceived that the types of materials used, the daily activity of the students and the possibility of constructing learning are important points for the teacher when dealing with practical activities in class.

Keywords: Experimentation. Science Education. Constructivism.

\section{Concepciones y prácticas de experimentación en los años iniciales de la Enseñanza Primaria}

Este estudio se caracteriza por ser una investigación cualitativa relacionada a procedimientos escolares y concepciones de docentes sobre experimentación, actividad instrumental o clase práctica. Por ello, se realizaron entrevistas con profesores actuantes en los años iniciales de la enseñanza primaria de escuelas públicas del municipio de Rio Grande/RS, junto con observaciones de sus clases, con el fin de analizar la manera por la cual la experimentación es utilizada en el proceso de enseñanza y aprendizaje de ciencias. A través de los datos recolectados, se percibe que los tipos de materiales utilizados, el cotidiano de los alumnos y la posibilidad de una construcción de aprendizaje son puntos importantes para el profesor al manejar actividades prácticas en su clase.

Palabras clave: Experimentación. Enseñanza de Ciencias. Constructivismo. 


\section{Introdução}

Ao pensar o ensino de ciências nos anos iniciais do ensino fundamental, muitas vezes o associamos com o desenvolvimento de experimentos ou atividades práticas termos que utilizaremos como sinônimos neste artigo. Cultivar feijões em algodão, selecionar caules de diferentes plantas e verificar os estados físicos da água são práticas muito corriqueiras. Todavia, a experimentação vai além de realizar alguns procedimentos, pois busca fomentar a aprendizagem dos estudantes, mobilizando estruturas cognitivas do sujeito perante a atividade. No mesmo sentido, para alunos dos anos iniciais, a experimentação pode configurar-se, também, como uma ferramenta lúdica, trazendo um aspecto motivacional. Igualmente, os livros didáticos e os documentos legais indicam as atividades práticas como um recurso metodológico de ensino desde o início da escolarização.

Neste contexto, a experimentação parece ocupar um importante papel no ensino de ciências, tanto nas práticas de fato efetuadas em sala de aula quanto na previsão legal e curricular. Por outro lado, os modos de realizar atividades práticas e de desenvolvê-las com os estudantes são os mais diferentes. Temos a hipótese de que isso decorre da sustentação epistemológica que alicerça esse recurso metodológico. Assim, nós nos propomos a investigar qual a ideia que os professores dos anos iniciais têm sobre a experimentação, bem como a relação com os modelos epistemológicos que subsidiam suas escolhas e ações.

\section{Experimentação e epistemologia no ensino de ciências}

Quando pensamos nas práticas escolares de sala de aula, podemos dizer que existem, de maneira geral, três modelos principais que inspiram as noções de ensino e aprendizagem (Becker, 2001; Silva, 2010). Estes três modelos sustentam-se em diferentes concepções epistemológicas e interferem de forma direta nas práticas pedagógicas desenvolvidas pelos professores. Pretendemos aqui discutir de que maneira estas três correntes epistemológicas podem surgir nas concepções dos professores com relação ao uso da experimentação em aulas de ciências nos anos iniciais. Partimos da ideia de que a aprendizagem não é um fenômeno isolado do ensino, nem tampouco pode acontecer sem influência das noções teóricas e epistemológicas dos docentes.

\section{A experimentação no modelo empirista}

O empirismo é uma corrente epistemológica que considera o conhecimento como um elemento exterior ao sujeito, sendo os processos de aprendizagem uma internalização dos estímulos do meio. Segundo Baggio, "na filosofia moderna o empirismo 
tornou-se uma doutrina que afirma a precedência do mundo objetivo sobre a cognição humana, que se limita a fornecer significado ou compreensão a uma realidade autônoma e previamente existente, colocando-se em oposição ao idealismo" (2006, p. 15). Assim, o modelo empirista se caracteriza pela crença de que o conhecimento "é algo que vem do mundo do objeto (meio físico ou social); portanto, o mundo do objeto é determinante do sujeito, e não o contrário" (Becker, 2008, p. 12). Podemos dizer que a inteligência, neste caso, é formada a partir do que recebemos do meio externo, ou seja, do "mundo dos objetos", que já está posto; precisamos apenas nos apropriar dele. Tal visão "concebe a produção do conhecimento científico como um processo único, verossímil, do ponto de vista lógico, e cuja validade independe do contexto" (Harres, 2008, p. 39).

Nesse sentido, a ciência é uma verdade incontestável. Sua validade é defendida e comprovada pelo método científico, o qual não permite a existência de dúvidas quanto ao conhecimento produzido por ela. No processo indutivista do método científico, todo conhecimento é originado na observação e na experimentação, seguidas por uma generalização indutiva, a formulação de hipóteses; posteriormente se busca a verificação, que pode acarretar em uma confirmação ou não, sendo, ao final do processo, a formalização do conhecimento. Abimbola apud Harres (2008), apresenta os pressupostos da visão empirista: a) A observação é imparcial, não muda nem quando o fazem os conceitos científicos; b) 0 conhecimento aumenta em um sentido cumulativo: os novos conceitos e teorias integram os antigos e os superam; cl 0 importante é a estrutura lógica dos produtos da investigação científica e a sua validação por critérios objetivos.

Em termos pedagógicos, o professor sustentado por uma epistemologia empirista acredita que seus alunos aprendem unicamente por determinação dos modos como organizam os estímulos sensoriais em situações de ensino. Em outras palavras, para este professor, a aprendizagem se dá pela noção de que o meio é radicalmente responsável pelas nossas aquisições, e que frente a um novo objeto somos sempre considerados tais quais folhas de papel em branco, uma vez que o meio ainda não tenha fornecido elementos para esta ou aquela aprendizagem. Coll (1994) descreve essa sala de aula como um meio onde as conversas são encaradas como indisciplinas que prejudicam o desenvolver da aula, pois é necessário haver silêncio para que o professor possa transmitir o conhecimento e para que o aluno possa entender o que o professor está falando.

E que implicações esta concepção epistemológica tem para a atividade de experimentação na sala de aula? Para este professor, ele é o centro da relação no processo pedagógico, pois é quem detém o saber. É ele quem realizará o experimento, pois acredita que "a experimentação, de forma dominante, é compreendida e desenvolvida como modo de demonstrar teorias estabelecidas" (Gonçalves; Galiazzi, 2004, p. 238). 
Haja vista o pressuposto de que o aluno nada sabe, então não seria útil nem desejável que este aluno fizesse seus próprios experimentos, uma vez que ele não teria condições para sair-se bem em tal atividade. Nesse caso, a experimentação assume um aspecto de demonstração ou comprovação, tendo seu papel na mobilização de outros estímulos externos, tais como o tocar e a visão.

\section{A experimentação no modelo apriorista}

0 apriorismo ou idealismo é uma corrente epistemológica que na sua essência se opõe ao empirismo. Se, para este, o meio é determinante para a aprendizagem, para aquele o sujeito é a origem do conhecimento. Desdobrando-se em uma relação pedagógica, o aluno passaria a ser o centro do processo pedagógico, determinando a relação de ensino e aprendizagem. Dessa forma, percebemos que, no apriorismo, acredita-se que todo conhecimento é elaborado autonomamente pelo sujeito com relação ao objeto ou ao contexto em que aquele está inserido. Nesse modelo, não é a metodologia do professor que determinará a aprendizagem: as condições do sujeito é que irão possibilitar a obtenção de conhecimentos. Conforme afirma Baggio (2006, p. 19), "as possibilidades do conhecimento pertencem ao sujeito". Portanto, podemos compreender que, para este modelo, o conhecimento não provém das experiências com o meio. Há, assim, uma forte predominância da maturação biológica nas questões da aprendizagem.

Nesse modelo, o professor "renuncia àquilo que seria a característica fundamental da ação docente: a intervenção no processo de aprendizagem do aluno" (Becker, 2008, p. 91). 0 professor apriorista acredita que seu aluno aprende porque possui características a priori ou inatas que o permitem aprender. 0 que seriam estas características? “[...] aquilo que é posto antes como condição do que vem depois [...] a bagagem hereditária" (idem, p. 91). Ou seja, aprendemos porque temos na nossa herança genética os elementos que permitirão nossa aprendizagem. Ou ainda, aprendemos porque existem condições a priori que permitem que possamos aprender.

Nesse sentido, basta que o meio nos permita despertar nossos conhecimentos e, consequentemente, aprender. Não é necessária a intervenção do professor, e tanto melhor seria se ele muito pouco interviesse no processo. No entanto, segundo Becker (ibidem, p. 92), “o apriorismo, como pano de fundo da explicação do desenvolvimento cognitivo, nunca se manifesta de forma explícita, teorizada. Manifesta-se, antes, como algo que se ignora, mas que é apontado como 'só podendo ser isso'”. Assim, o apriorismo está muito mais em função das crenças do professor com relação à aprendizagem do que diretamente relacionado às suas escolhas metodológicas em sala de aula. Por isso, para um professor apriorista, possivelmente a atividade de experimentação teria 
sentido caso fosse uma vontade do sujeito. Se os alunos em aula decidissem realizar alguma atividade de experimentação, ela teria validade para o processo de aprendizagem na medida em que fosse feita por eles, pois o professor compreenderia que seus alunos, ao procurarem a atividade, estariam prontos a aprendê-la, ou dela tirariam, por si mesmos, o máximo proveito. Além do mais, o apriorismo serviria para explicar por que alguns não aprendem pela experimentação: neste caso não seriam possuidores de dom ou talento inatos para serem cientistas e investigadores.

\section{A experimentação no modelo construtivista}

0 terceiro modelo que se pode identificar (Becker, 1994, 2008) com relação às epistemologias presentes na ação pedagógica em sala de aula, é o modelo construtivista. Em geral, este modelo tem suporte em teorias como a "psicologia genética de Piaget, na obra pedagógica de Paulo Freire, em pedagogias de fundamentação marxista: na psicologia do desenvolvimento de Vigotsky, em Gramsci, Wallon" (Becker, 2008, p. 11). De acordo com este modelo epistemológico, o foco está na interação entre sujeito e objeto, conforme escreve Piaget (1087, p. 386):

[...] as relações entre o sujeito e o seu meio constituem numa interação radical, de modo tal que a consciência não começa pelo conhecimento dos objetos nem pelo da atividade do sujeito, mas por um estado indiferenciado; e é desse estado que derivam dois movimentos complementares, um de incorporação das coisas ao sujeito e outro de acomodação às próprias coisas.

Em outras palavras, é na interação (ação entre) sujeito e objeto que encontramos a fundamentação teórica para a construção dos saberes no sujeito. É na medida em que conhecemos o mundo que construímos elementos intelectuais para lê-lo e transformálo (Piaget, 1975). Com isso, podemos compreender que, com relação à aprendizagem, existem dois polos importantes: um deles é o sujeito, que assimila o mundo e o transforma, e o outro é o próprio mundo, que ao ser assimilado pelo sujeito modificase e com ele interage. Assim, o construtivismo recoloca o professor no lugar de

[...] trabalhador intelectual [...] no lugar de alguém que tem compromisso [...] de conhecer o desenvolvimento dos educandos, de compreender profundamente os conteúdos científicos para a partir deles realizar transposições didáticas, criar metodologias singulares e pessoais, devolvendo-lhe um pouco da dignidade roubada (Moll; Barbosa, 1999, p. 116). 
Nessa ideia, o professor se torna o sujeito que organiza as aulas de forma que sejam possíveis as construções de conhecimento. Ele "tem de criar atividades nas quais os alunos possam manipular e explorar os objetos, criar regras de conduta [...] criar liberdade intelectual para que eles não tenham receio de expor suas ideias e fazer perguntas" (Carvalho et al., 1998, p. 35), sendo importante lembrar sempre "o aluno como sujeito que aprende sem que ninguém possa substituí-lo nessa tarefa" (ibid), já que o aprender é um processo mental construtivo.

Então, como um professor construtivista utilizaria uma atividade de experimentação na sala de aula? Provavelmente, para este professor, toda aula necessita partir de questionamentos, pois estes revelam o que já conhecemos do objeto a ser conhecido e o que desejamos aprender. Nesse sentido, concordamos com Gonçalves e Galiazzi (2006, p. 246), que entendem que "o conhecimento tem como origem uma pergunta, logo acreditamos que o primeiro movimento de uma atividade experimental precisa ser o questionamento". A atividade experimental, neste fundamento epistemológico, traz a possibilidade de o professor problematizar aquilo que está ocorrendo com o experimento. Seria o caso de fazer perguntas com a intenção de provocar dúvidas e desestabilizar as concepções que os alunos já criaram em torno do fenômeno; podemos dizer, em suma, desequilibrar o sujeito, antes, durante e depois da experimentação. Isto ocorre porque o professor "compreende que o aluno só aprenderá alguma coisa, isto é, construirá algum conhecimento novo, se ele agir e problematizar sua ação" (Becker, 1994, p. 92).

Ainda conforme afirmam Gonçalves e Galiazzi (ibid., p. 247): "um dos aspectos que a atividade experimental precisa favorecer é a análise das teorias do grupo sobre os fenômenos estudados", isto é, a atividade experimental precisa ser um elemento que favoreça o diálogo entre os colegas, no intuito de discutirem suas teorias e colocá-las à prova pela argumentação. Isto seria possível de ser pensado em uma sala de aula onde o professor não se veja como o centro do processo cognitivo, nem veja somente seu aluno como determinante de suas próprias aprendizagens, mas sim estabeleça uma relação entre ambos, juntamente com o meio e outros determinantes dessas relações. Isso equivale dizer que, dentro dessa concepção epistemológica, o professor não apresentará o experimento para seu aluno com a intenção de que este apenas observe o que está ocorrendo. Ele irá problematizar as teorias que o aluno já traz de seu contexto cultural e, com isso, interferir no processo de aprendizagem do mesmo. A intencionalidade pedagógica do professor será a de criar condições para que os alunos possam reconstruir suas hipóteses, e não para que comprovem esta ou aquela teoria estudada em aula. 


\section{Delineamento do estudo e aspectos metodológicos}

Para podermos compreender as escolhas metodológicas dos professores com relação às atividades de experimentação nos anos inicias, utilizamos o cruzamento de diferentes fontes de evidência a fim de mapear e identificar modos de atuação e compreensão dessa abordagem no âmbito da sala de aula. Procuramos investigar o tema por meio da observação, de entrevistas e da análise de documentos com o objetivo de compreensão dos processos escolares e de qualificação do ensino de ciências nos anos iniciais. 0 recorte do estudo insere-se em um projeto mais amplo, inspirado e adaptado a partir das metodologias de pesquisa em consórcio (Barros et al., 2008; Hallal et al., 2009). Em termos gerais, trata-se da realização de uma investigação coletiva, com diversos temas correlatos no campo do ensino de ciências dos anos iniciais. As vantagens dessa modalidade conjunta são a possibilidade de se contar com múltiplos olhares sobre o mesmo caso, enfoques sob diferentes aspectos, além da reflexão coletiva e cooperativa na coleta e análise de dados.

Em termos práticos, após definidas as temáticas específicas a serem investigadas, realizamos reuniões com professores das escolas investigadas para uma entrevista aberta e informal, na qual relataram situações do cotidiano de suas salas de aula. A partir dessa ação exploratória elaboramos um protocolo de investigação para entrevistas semiestruturadas (Lüdke; Andre, 1986). A coleta realizada de forma coletiva permitiu um número maior de dados, expandindo a amostra em quantidade e qualidade, a fim de ampliar as compreensões dos processos. Além disso, no caso da experimentação, os outros pontos pesquisados trouxeram subsídios que permitiram compreender este foco de investigação. De fato, o entrecruzamento de temas ${ }^{1}$ permitiu a tessitura de diversos fios na análise da temática, alcançando níveis mais profundos de apreciação e de reflexão sobre as práticas e concepções escolares.

Após as entrevistas, foram realizadas atividades de observação nas escolas, a fim de registrar o desenvolvimento de aulas práticas e os procedimentos de fato adotados. As observações foram registradas em diários de campos (Bogdan; Biklen, 1994) e compartilhadas nas reuniões coletivas entre os pesquisadores que compunham o consórcio. Em seguida, houve estudo e análise documental (Gil, 1999) sobre as principais referências legais existentes na área de estudo e no espaço escolar investigado. Foram considerados os Parâmetros Curriculares Nacionais para a área de ciências (Brasil, 1997a) e os Temas Transversais nas temáticas concernentes (Brasil, 1997b), ambos

1. 0 consórcio abrangeu as temáticas da experimentação, dos jogos, das dificuldades de aprendizagem, do ensino de astronomia, do ensino de saúde e do uso das tecnologias, todas no âmbito dos anos iniciais. 
referentes ao primeiro e segundo ciclo do ensino fundamental. Também foram incorporados ao conjunto de dados o Projeto Político-Pedagógico das escolas investigadas e as sugestões curriculares que são recebidas pelos professores. Esses documentos, juntamente com as observações realizadas e as entrevistas coletadas, sofreram processo de triangulação e análise apurada, a fim de se compreender o modo como se diz que faz (entrevista), aquilo que legalmente se deveria fazer (documentos) e aquilo que realmente se faz (observações).

Com relação à produção de informações, o estudo originou-se da investigação realizada no ano de 2011 em escolas da rede pública municipal da cidade do Rio Grande/RS que se dispuseram a colaborar com o estudo. Foram entrevistados 22 professores, todos com exercício da docência nos anos iniciais do Ensino Fundamental. Durante as observações foram acompanhadas 8 turmas do $1^{\circ}$ ao $5^{\circ}$ ano, com média de 30 alunos em cada um dos grupos, totalizando 20 observações, que duraram 1 hora, em média.

\section{Análise e Discussão dos Dados Coletados}

Os processos de exame dos dados referendaram-se na análise de conteúdo (Bardin, 2002), com o objetivo de construir categorias representativas dos modos de se conceber e utilizar a experimentação. Analisando os dados coletados por meio de das fontes de evidência (entrevista, observação e análise documental), foram construídas três grandes categorias que se referem aos modos como a experimentação se relaciona (a) com os materiais utilizados, (b) com o cotidiano dos alunos e (c) com a aprendizagem durante as atividades.

\section{a) Experimentação e materiais}

Observamos que, em algumas das práticas de experimentação dos professores deste estudo, um elemento crucial para definir a qualidade do experimento é o material a ser empregado. Dessa maneira, acredita-se que o status atribuído aos objetos disponíveis pode revelar noções epistemológicas e de aprendizagem que sustentam a prática experimental nas aulas de ciências. Vejamos os estratos de alguns protocolos de coleta:

Como você acha que o uso de atividades práticas poderia ajudar no ensino de ciências? “Eu acho que, por exemplo, usando jogos de quebra-cabeça [...], pode levar o aluno a entender melhor porque é bonito e é colorido, chama mais a atenção deles" (Anotações de campo, pesquisador $\mathrm{B}, 12 / 09 / 2011)$. 
Como as atividades práticas ajudam os alunos? "Elas ajudam com certeza. Através desse tipo de atividade podemos utilizar diversos materiais, como, por exemplo, jogos sobre o planetário, quando vou iniciar a trabalhar o sistema solar. Essas atividades possibilitam a brincadeira, dar risadas e se aprende também, mas para isso acontecer tem que 'puxar para o conteúdo'. As atividades práticas são mais para se usar no início da aula, para empolgar os alunos sobre determinado assunto. Eles estarão vendo e manuseando o material que levamos para a sala. É legal" (Anotações de campo, pesquisador $G, 12 / 09 / 2011$.

Em princípio, a aparência dos objetos, ou seja, o componente visual presente no material a ser utilizado é o que motiva ou não o seu uso. Em geral, os materiais são pensados com o intuito de "chamar a atenção" dos alunos, devido à "quebra" da rotina de sala da aula. Outro aspecto importante na fala dos entrevistados é o momento em que os materiais são introduzidos. Em geral, ocorrem da seguinte maneira:

Como você realiza uma atividade de experimentação? “Apresento oralmente e com uma demonstração, ou faço só a demonstração. É a melhor forma." E por que fazes assim? “Porque na demonstração é mais fácil para eles entenderem. Eles estarão observando atentamente" (Anotações de campo, pesquisador D, 12/09/2011).

(Observação turma do $5^{\circ}$ ano): A professora, após trabalhar todos os sistemas do corpo humano de forma expositiva ao longo do ano, leva os alunos para o laboratório de informática. Lá se encontra um armário onde se tem um modelo anatômico do corpo humano com os diversos órgãos que o compõe. Ela solicita que os alunos fiquem em torno de uma mesa retangular, em silêncio, e que prestem bastante atenção, que ela irá mostrar como são os órgãos; menciona que: "No final, quando eles estiverem todos los órgãos) na mesa, vocês vão poder tocar, mas agora só me ouçam. Vamos ver se vocês aprenderam tudo que vimos sobre os sistemas em aula." A professora inicia retirando os pulmões do modelo, que são os órgãos mais externos, e vai falando sobre eles. Após, retira o coração e fala sobre ele, e assim vai seguindo com todos os órgãos. Os alunos em certos momentos tentam tocar nos órgãos em cima da mesa, mas são reprimidos rapidamente. Em seguida ela mostrou todos os órgãos e os alunos podiam "com cuidado" tocá-los (Anotações de campo, pesquisador A, 15/09/2011).

Evidencia-se assim que o professor utiliza apenas a demonstração na atividade prática, sendo sustentado por uma postura empirista. Ele assim o faz por acreditar que basta o aluno ver um experimento ser demonstrado para que aprenda aquele conteúdo. 
0 fato de estar exposto ao estímulo sensorial garante, por si só, uma boa aprendizagem, em condições intelectuais adequadas. Para este professor, podemos dizer que a aprendizagem e o ensino são uma via de mão única, na qual o objeto determina as aprendizagens que o sujeito vai adquirir no decorrer da demonstração.

No escopo dessa categoria do material nas atividades de experimentação surgiram falas de professores que relatam a ausência de material adequado nas escolas, sendo isto considerado um empecilho para a realização de aulas práticas. Ao serem indagados sobre as atividades práticas propostas pelos livros didáticos, mencionaram que algumas são reestruturadas para se adaptar às condições de material e tempo que se tem, mas que não é possível realizar a maioria, pois consideram a linguagem muito complexa e pouco compreensível. Percebemos isso de modo contundente na fala de um dos entrevistados. Quando indagado sobre o tipo de livro que utilizaria para pesquisar experimentos para suas aulas, respondeu-nos: "Um que não tenha vocabulário científico, próprio para as crianças, [...] Que não é maçante, nem tenha características científicas." Outros professores ainda dizem que "depende do livro, alguns trazem coisas boas, mas tem vezes que o material que pede a escola não tem." Todavia, alguns dados de observação mostram um cenário diferente:

(Observação da escola X): Ao chegar à escola, um membro da equipe diretiva nos direciona para um local que possuía uma série de caixas com vidrarias, equipamentos, como microscópios e demais instrumentos que seriam para construir um laboratório na escola. Esses se encontravam em estado de conservação adequada e com jeito de que nunca tinham sido utilizados (Anotações de campo, pesquisador C, 21/09/2011).

(Observação da escola Y): Ao conversarmos de modo informal com uma professora da escola, esta nos relatou que a escola não possuía laboratório de ciências, devido a não ter espaço físico, mas mencionou que existem materiais de boa qualidade na escola. Ela nos levou até os materiais, e estes consistiam em modelos anatômicos do corpo humano e de animais. Tais materiais encontravam-se empacotados e, segundo ela, poucos professores usam, ela acredita ser a única, e menciona: "Acho que os colegas não sabem usar ou têm medo que os alunos danifiquem o material" (Anotações de campo, pesquisador $\mathrm{E}, 15 / 09 / 2011$.

Para avançar na análise dos dados e verificarmos as propostas que os livros sugerem, optamos pela coleção mais utilizada na rede municipal estudada ${ }^{2}$. Na análise, constatou-

2. Os livros analisados foram os da coleção Aprendendo Sempre, distribuídos pelo Governo Federal para escolas municipais e destinados às turmas do $2^{\circ}$ ao $5^{\circ}$ ano do Ensino Fundamental, nos anos de 2010 a 2012. 
se que pouco material é exigido e há atividades em que se trabalha apenas com entrevistas ou com a montagem de peças de teatro. Em geral, os materiais mais solicitados são garrafa plástica, caixinhas de papelão, papel, lápis de colorir, sementes e frutas, ou seja, materiais de baixo custo e que estão presentes no cotidiano dos professores e dos alunos. Em resumo, o que os professores entendem por ausência de material adequado para a realização de atividades experimentais na sala de aula são aqueles sofisticados, presentes em laboratórios especializados, capazes de chamar a atenção e possivelmente despertar o interesse dos estudantes. Nota-se, novamente, a questão do imaginário que gira em torno da prática científica.

De fato, podemos constatar que a ideia que se tem de um “verdadeiro" experimento no ensino de ciências é a daquele realizado em um laboratório específico, com uso de instrumentos como becker e pipeta, líquidos coloridos e fumaças exóticas. Para uma parcela considerável de professores há a crença de que, para ser considerada um experimento de ciências, uma atividade escolar deve reproduzir ou se aproximar das práticas de laboratório vendidas pela mídia. Por isso, necessita de materiais próprios ou sofisticados. 0 uso de um jaleco e do microscópio garantiria à atividade um status de experimentação. Desse modo, as propostas do livro didático acabam não sendo vistas como atividades experimentais, em função de sua aparente simplicidade. Além disso, o risco de uma experimentação não “dar certo” é muito grande. 0 uso de materiais reciclados ou adaptados não forneceria uma precisão científica. Então, se o professor não dominar as técnicas de determinado experimento, pode ser que tudo saia mal, o que implica a não apropriação devida de conceitos científicos e pedagógicos. Então nos questionamos: qual o papel do erro em uma atividade experimental?

Em geral, nas respostas que obtivemos, o erro é tido como algo indesejável nas atividades de experimentação. Ele deve ser descartado quando surge. Vejamos alguns trechos de respostas da seguinte questão: “Quando realizas atividade experimental, o que você faz, quando acontece um resultado inesperado?"

Sujeito 1: "Explico qual seria o resultado esperado e procuro saber por que deu errado, para dar um retorno aos alunos."

Sujeito 2: "Faço de novo. Deveria tentar explicar o porquê de ter dado errado, acho legal, mas não faço."

Sujeito 3: "Explico que não era essa a proposta. Explico o que possivelmente deu errado."

Sujeito 4: "Retomo, tem que fazer novamente."

Sujeito 5: "Resolvo e volta tudo ao normal."

(Fonte: Entrevistas realizadas com professores das escolas de educação básica). 
De modo geral, os professores acreditam que o erro, embora inevitável, deva ser descartado do processo experimental. A ideia geral é a de que se deva sempre chegar ao resultado "correto". Por isso, quando o erro acontece, o ideal é retomar a atividade e fazê-la dar certo. Essa ideia é possivelmente decorrente do mito de que a ciência é feita de acertos e êxitos. Vende-se a ideia de que não há espaço para o erro nas práticas científicas. 0 conceito de ciência que é transmitido aos alunos nesse tipo de prática experimental é o de que, na ciência, todo saber é construído com base em processos que funcionam e são exitosos. É reforçada a ideia de que a ciência é um saber absoluto e verdadeiro sobre o mundo, uma vez que não há espaço para a construção e para o erro. Nesse sentido, os materiais e as atividades têm de carregar em si essa dimensão de precisão e especificidade, não podendo servir a outras coisas ou situações não científicas.

\section{b) Experimentação e cotidiano}

De acordo com os dados coletados nas observações e nas entrevistas realizadas, notamos que os experimentos escolares são utilizados, em geral, com o intuito de abordar temas dos conteúdos curriculares de maneira diferenciada. Além disso, evidencia-se uma forte intenção de aproximação das atividades práticas com os problemas do cotidiano a fim de produzir maior significado nas aprendizagens. Todavia, ao analisarmos mais a fundo, foi possível identificar diferentes formas e motivos pelos quais o cotidiano é relacionado com a experimentação. Destacam-se, nessa relação entre cotidiano e experimentação, os seguintes momentos de entrevista:

O que você utiliza para trabalhar conteúdos de ciências? "Eles têm na realidade as plantações. Como faz parte da realidade deles, fica mais fácil de relacionar com os conteúdos." E como você trabalha? "Eu faço uma horta e vou mostrando os modos corretos de ver os conteúdos que estão ali envolvidos. Partindo da realidade do aluno, é muito mais fácil" (Anotações de campo, pesquisador C, 12/09/2011).

Como você introduz um conteúdo? "Parto da realidade dos alunos e do cotidiano deles. Aí vou introduzindo os conteúdos. Tem de partir da realidade para ter significado." E como fazes para introduzir os conteúdos? "Vou explicando em cima da realidade deles, mostrando os conceitos e os conteúdos que estão ali envolvidos" (Anotações de campo, pesquisador $E, 12 / 09 / 2011$.

Ao analisar estas falas, é possível evidenciar que o cotidiano e o entorno do estudante são considerados como um ponto de partida e um modo de relacionar os conteúdos. 
De fato, o professor não modifica sua hipótese curricular, em termos de tempo e ordem das atividades, mas as compara com o dia a dia dos estudantes. Nesse sentido, entendemos que é importante distinguir o contexto e o significado de um conteúdo. Ensinar com significado refere-se a processos didáticos que procuram trabalhar com problemas dos próprios alunos e que se configuram como desafios para os estudantes, isto é, com os conteúdos a serviço das necessidades emergentes. Diferentemente, ensinar com contexto significa acrescentar à lista habitual de conteúdos uma situação, fato ou comparação que permita ver uma aplicabilidade do saber que o docente procura ensinar. A partir dos dados coletados, identificamos que a relação do cotidiano com a experimentação é entendida nesse segundo marco, isto é, de atribuir um contexto e um modo de exibir o conteúdo com alguma relação com as vivências das crianças. Ainda alguns professores mostraram em suas falas que nas aulas de ciências buscavam levar os alunos a modificarem seus comportamentos, focando suas aulas em exemplos práticos e úteis ao dia a dia das crianças. Um dos sujeitos enfatiza tal ideia ao dizer que “[...] a relação entre ciência e o dia a dia deles é estreita. Gosto de trabalhar os hábitos de higiene e a água, para conscientizá-los de que devem cuidar do corpo e do planeta. Gosto de trabalhar ciências com eles" (Anotações de campo, pesquisador $\mathrm{Cl}$.

Além disso, percebe-se que essa ação prática sobre o cotidiano, realizada na escola, pouco se diferencia dos comportamentos usuais dos alunos, isto é, não há uma evolução no conhecimento. Na verdade, nesse tipo de atividade, não se trata de uma experimentação sobre o cotidiano, mas de uma releitura das vivências corriqueiras, na qual a escola traduz cientificamente as situações, pois o ensino formal seria o agente único e oficial para validar as aprendizagens necessárias para o bom funcionamento da vida pessoal e social do sujeito. Observamos, em uma aula de $4^{\circ}$ ano, uma professora trabalhando o conteúdo das partes da planta. Inicialmente ela coloca uma pequena violeta diante da turma e pede que, um por um, a examinem com cuidado e atenção, podendo tocá-la e cheirá-la. Após, ela pede a eles que digam algumas características dessa planta, ao que respondem com frases curtas ou palavras soltas, como: "bonita”, “fedida”, “tem flores brancas”, “possui duas folhas”, etc. Ao finalizar essa parte da atividade, a professora entrega uma folha com um desenho de uma árvore, no qual em cada parte da planta há uma pequena frase descrevendo-a. A professora, então, diz aos alunos que as plantas são compostas de raiz, caule, folhas, flores e frutos. Dita a importância de cada uma dessas partes para a sobrevivência das plantas e encerra o assunto.

Todas as crianças já tiveram algum tipo de experiência com uma planta, na qual perceberam que elas possuem folhas, troncos ou caules, flores, raízes e alguns frutos. 
0 que acontece é que esse cotidiano vivido pelas crianças desde sua primeira infância não é visto como algo científico. Isso porque somente a escola poderia transformar esses conhecimentos em saberes. No entanto, as crianças da aula descrita acima não puderam aprender nada de novo nessa aula de ciências. Podemos dizer que não tiveram motivos para terem curiosidade? Sim, certamente elas teriam muito a perguntar sobre as plantas, porém não tiveram espaço para isso nessa aula demonstrativa, uma vez que ela não permite a compreensão de um saber, mas sim a imposição de verdades.

Essa prática mostra que os docentes preferem e acreditam ser necessário guiar os alunos durante as atividades. Acreditam que os alunos precisam de um exemplo para ser seguido, pois não teriam imaginação para realizar as atividades sem um roteiro predefinido. De acordo com Rosito (2008, p. 200), “uma experimentação demonstrativa propõe atividades práticas voltadas à demonstração de verdades estabelecidas”, assim, o aluno estaria com o papel de receptor daquele conhecimento que the está sendo transferido. De modo geral, na relação experimentação e cotidiano, percebemos que a situação experimental reflete uma posição empirista dos professores. Eles acreditam que o estudante, ao estar imerso na atividade prática, estará realizando aprendizagens, por meio do contato com os objetos. A vivência a que se referem é essa possibilidade de contato com o material a ser estudado ou experimentado. É o fato de, por exemplo, os alunos poderem tocar nos diferentes tipos de solo ou nas partes de uma violeta, mesmo que, em diversas outras situações de suas vidas, eles já tenham tido essas experiências.

\section{c) Experimentação e aprendizagens}

A partir dos dados coletados, passamos a elaborar um entendimento sobre as ideias de aprendizagem que subsistem às práticas experimentais, sobretudo àquelas que privilegiam o aprender como uma possibilidade de construção. Percebemos que há grande influência nos discursos dos professores da concepção epistemológica construtivista. Todavia, nem sempre aquilo que o professor diz é necessariamente o que realiza em sua sala de aula. Percebemos então que há algumas dicotomias entre discurso e prática. Por meio das observações e das entrevistas, ficou claro o predomínio da concepção empirista sobre a concepção construtivista. Observemos os seguintes trechos, retirados das entrevistas realizadas no momento em que os professores responderam a este questionamento: "Como as atividades práticas ajudam os alunos na sua aprendizagem?"

Sujeito 1: "Os ajudam a entenderem melhor o conteúdo. Com a prática eles estão visualizando. Eles se dão conta melhor daquilo que estão aprendendo." 
Sujeito 2: "Nas atividades práticas os alunos tocam e eles mesmos realizam as coisas. Assim eles podem criar hipóteses, tirar conclusões e construir conhecimento."

Sujeito 3: "Tudo que é experienciado e vivido se aprende. Como na experiência do feijão, que se vê na prática seu crescimento."

Sujeito 4: “Só fazendo que eles constroem o conhecimento. Se não fica só na teoria. Fazendo, eles entendem tanto o porquê quanto o que é."

Sujeito 5: “Ajudam porque eles vivenciam, eles constroem o conhecimento, e tiram outras conclusões além do esperado."

Sujeito 6: “Ele é o sujeito da ação, ele fixa melhor aquilo que queremos ensinar."

Sujeito 7: “Ajudam o aluno a aprender mais. 0 que vivenciam, demonstram mais facilidade em aprender. Não tem a coisa pronta."

Sujeito 8: “Os alunos gostam, causa uma realização pessoal. Manifestam interesse porque saem da rotina."

Sujeito 9: “Ao fazer uma atividade prática, eles interagem mais do que uma atividade somente teórica."

Sujeito 10: "Porque eles vão poder ajudar a fazer. É concreto, eles podem aprender mais fácil. Com a atividade, tem mais material concreto para mexerem, isso ajuda muito."

(Fonte: Entrevistas realizadas com professores das escolas de educação básica).

Todos os professores acreditam que a atividade experimental, de um modo ou de outro, possibilita a aprendizagem. No entanto, percebemos nas falas que existem duas grandes concepções nas suas respostas: uma é a de que a atividade experimental auxilia a aprendizagem na medida em que permite a construção de conhecimentos por meio da interação com os objetos estudados. Por outro lado, acreditam que a atividade experimental possibilita a aprendizagem porque os alunos estarão fixando melhor os conteúdos, por meio da ação física sobre os objetos. Nesse mesmo sentido, alguns docentes acreditam que a atividade experimental auxilia na aprendizagem porque os alunos estarão tocando, mexendo, visualizando os objetos. Acreditam que, dessa forma, é mais fácil para o aluno entender o conteúdo que está sendo abordado na experimentação. 0 material concreto é visto como importante instrumento para possibilitar a aprendizagem, porque se acredita que os alunos podem agir sobre o objeto e, consequentemente, essa ação vai gerar uma aprendizagem.

Percebe-se que a ação é entendida apenas em sua dimensão sensorial, pois o sujeito que toca, vê e sente tem possibilidade maior de compreender ciências do que aquele que tem aulas somente teóricas. Tais ações estão ligadas às características mais aparentes do objeto e não são suficientes para que se ultrapasse um nível mais superficial de conhecimento. Segundo Piaget (1977), trata-se do conhecimento da ação 
material sem conceituação, isto é, o agir pelo agir: não há tempo para a construção de conhecimentos sobre o objeto. A conceituação é um nível mais complexo de conhecimento, que exige, além da interação física, a interação cognitiva com o objeto de estudo.

A concepção de que "só fazendo que se aprende" acaba se reafirmando quando questionamos como o professor trabalha as atividades práticas em suas aulas, ou seja, quando queremos compreender sua concepção metodológica com relação à atividade experimental. Um dos professores nos responde que: "Vou fazendo e eles me acompanham, sempre juntos. Quando eles têm dificuldade, eu e os colegas auxiliamos." Aqui percebemos que a ação prática do aluno está presente, mas controlada pelo professor. Ele é quem realiza o experimento primeiro, ele faz para que os alunos o acompanhem, como forma de garantir que a tarefa se desenvolva perfeitamente, sem erros. A aprendizagem, portanto, seria uma consequência da ação do professor, que mostraria aos alunos como devem prosseguir. Por sua vez, os alunos não precisam pensar em nada novo, basta seguir as instruções do professor. A atividade experimental, nessa aula, cumpre o mesmo papel que qualquer outro tipo de exercício de exemplo proporcionaria. A novidade não está na experimentação, ela serve apenas para comprovar algo já afirmado anteriormente.

0 entendimento de que a aprendizagem de ciências está vinculada ao prazer possibilitado pela atividade experimental é outro dado que surge com força nas entrevistas e observações realizadas. As atividades práticas são entendidas como meios motivacionais, isto é, elas dão o toque especial nas aulas dos professores. Ao sair da rotina, ao propor um experimento, o professor pode motivar os alunos a gostarem da aula e a participarem desta, como afirmou a professora: "Os alunos gostam, causa uma realização pessoal. Manifestam interesse porque saem da rotina." 0 prazer funcional ligado à experimentação é apenas um componente motivacional, segundo o que percebemos das falas e das aulas dos professores entrevistados. Vejamos a observação abaixo, realizada na aula de uma das professoras entrevistadas, em uma turma de $3^{\circ}$ ano:

A professora organiza a sala, colocando uma mesa ao centro com os seguintes itens: uma garrafa térmica, uma garrafa com água e um vasilhame com gelo. A aula é iniciada da seguinte forma:

- Pessoal, vamos estudar hoje os estados físicos da água. (Mostra a garrafa de água.) 0 que temos aqui? Como está a água aqui?

Os alunos respondem:

- É água! Molhada...

Ao que a professora responde: 
- Não! Ela está líquida! E agora, (mostrando um cubinho de gelo), o que vocês acham que aconteceu aqui com a água?

Uma menina responde prontamente:

- Ela foi colocada numa forminha, e depois no freezer. Daí ficou assim!

Ao que a professora complementa:

- Isso! Ela está em estado sólido! Ela está dura! - e prossegue a demonstração - E agora (pressionando a garrafa térmica para que saia a água ali armazenada), o que está acontecendo com essa água? Qual o estado dela?

Um aluno responde:

- Ela está em estado de vapor!

- Não! - responde a professora - Ela está em estado gasoso! Isso porque está muito quente!

- Ahhh... - respondem as crianças.

- Agora vou entregar a vocês uma folinha para colarem no caderno.

A folha era um pequeno texto que formalizava os conceitos dos estados físicos da água.

A aula de ciências foi encerrada com essa folha, colada no caderno.

(Anotações de campo, pesquisador B, 10/10/2011).

Nessa aula, percebemos que a atividade experimental na verdade é apenas uma atividade de demonstração. 0 gelo, a água quente e a água fria foram utilizados apenas para ilustrar os conteúdos que a professora gostaria que seus alunos aprendessem na aula. Apesar de as respostas dos alunos possibilitarem, em alguns momentos, à professora a discussão de suas teorias, aquelas acabam por ser ignoradas. Ao final da aula, ela nos relatou isto: "Faço atividades assim porque é mais concreto, eles podem visualizar os estados da água, por exemplo. É mais fácil para entenderem, do que se eu só fizesse desenho no quadro." Esta concepção de aprendizagem é, em sua essência, empirista. A professora acredita que, por meio dos sentidos, os alunos poderão aprender sobre os estados físicos da água. Para completar essa aprendizagem, ela thes dá os conceitos prontos, em uma folha que deverá ser colada no caderno, ou seja, ela demonstra o fenômeno, explica como ocorre e depois o formaliza em uma folha. Os alunos não participam, embora esse tipo de aula seja pensado justamente em favor de sua participação ativa na aula.

Em geral, os professores fazem uso de experimentações não porque estas de fato promovam a aprendizagem, mas porque tornam a aula mais atrativa; agrada mais aos alunos estarem diante de materiais "concretos" do que participarem de aulas exclusivamente teóricas, mesmo que em tese estejam fazendo a mesma coisa: recebendo informações do professor, sem necessidade de raciocinarem sobre o assunto. Ainda 
nas entrevistas, percebemos que há outras concepções permeando as compreensões dos professores com relação à atividade de experimentação e seu papel na aprendizagem dos alunos, conforme um dos entrevistados: "Ao fazer uma atividade prática, eles interagem mais do que se estivessem participando de uma atividade somente teórica." De qual interação este professor estaria falando?

Ao afirmar que a atividade experimental permite mais interação que aquela puramente teórica, o professor parte da premissa de que apresentar conceitos ou definições não é suficiente para garantir a aprendizagem dos mesmos. Por meio da interação com o fenômeno, ou objeto em questão, o aluno poderá experimentar de diversas formas os processos estudados, podendo assim testar suas hipóteses sobre tal assunto. Essa compreensão será possibilitada mediante a ação que o experimento irá proporcionar, mas cabe ressaltar que essa ação não é somente do sujeito sobre o objeto de conhecimento, mas se constitui uma interação, ou seja, ação recíproca entre sujeito e objeto. Piaget (1975) explica que o conhecimento é simultaneamente acomodação e assimilação entre sujeito e objeto de conhecimento. Dessa maneira, o progresso da inteligência ocorre em um duplo sentido de exteriorização ao eu, incorporando o novo, e de uma atividade intelectual progredindo em interiorização, ocasionando uma modificação interna.

Para ocorrer essa interação, a problematização é um recurso de grande importância, pois é uma possibilidade de fazer os alunos pensarem sobre o que ocorre no desenvolvimento de uma atividade experimental. Retomando o exemplo da aula observada, a professora poderia ter partido de questões para possibilitar aos alunos pensarem sobre suas hipóteses, por exemplo, de por que a água quente emana vapor ou, ainda, por que o frio faz com que a água congele. A pergunta é o meio pelo qual o professor pode conhecer o que pensam e o que sabem seus alunos, antes de iniciar a atividade em si, assim como expressa a ideia de uma professora: "Começo fazendo perguntas, problematizando, questionando, e depois proponho a atividade." Assim, problematizar seria uma forma possível de levar os alunos a uma aprendizagem voltada à atividade cognitiva, para além da atividade física, permitindo, de fato, a construção de conhecimento pelos alunos.

\section{Considerações finais}

Ao nos propormos investigar as práticas de experimentação no ensino de ciências dos anos iniciais, tínhamos a hipótese de que esta abordagem pudesse proporcionar processos de ensino e aprendizagem diferenciados, superando métodos tradicionais. Todavia, nota-se que a referência epistemológica dos sujeitos, mesmo que inconsciente, 
é fator determinante dos modos de ensinar. A tabela abaixo ilustra as relações entre os fundamentos epistemológicos, as práticas pedagógicas e as formas de abordar a experimentação.

Quadro 1 - Relações entre os fundamentos epistemológicos, as práticas pedagógicas e as formas de abordar a experimentação

\begin{tabular}{|c|c|c|c|}
\hline & $\begin{array}{l}\text { Características } \\
\text { epistemológicas }\end{array}$ & $\begin{array}{c}\text { Características } \\
\text { pedagógicas }\end{array}$ & $\begin{array}{l}\text { Características } \\
\text { das atividades } \\
\text { experimentais }\end{array}$ \\
\hline EMPIRISMO & $\begin{array}{l}\text { - O conhecimento } \\
\text { está fora do sujeito. } \\
\text { - A experiência } \\
\text { sensorial e os } \\
\text { estímulos } \\
\text { exteriores levam à } \\
\text { aprendizagem. } \\
\text { - Os modos de } \\
\text { conhecer } \\
\text { dependem de } \\
\text { condicionamento } \\
\text { do comportamento. }\end{array}$ & $\begin{array}{l}\text { - } 0 \text { professor é } \\
\text { detentor do } \\
\text { conhecimento. } \\
\text { - } 0 \text { ensino gera a } \\
\text { aprendizagem } \\
\text { através da } \\
\text { organização dos } \\
\text { estímulos. } \\
\text { - Aprendem todos } \\
\text { os que podem } \\
\text { absorver o que é } \\
\text { transmitido pelo } \\
\text { professor. }\end{array}$ & $\begin{array}{l}\text { - Demonstração da } \\
\text { prática. } \\
\text { - Repetição pelo } \\
\text { aluno do que foi } \\
\text { demonstrado. } \\
\text { - Materiais bem } \\
\text { organizados e } \\
\text { roteiros passo a } \\
\text { passo. } \\
\text { - Criação de um } \\
\text { cotidiano } \\
\text { artificializado. }\end{array}$ \\
\hline APRIORISMO & $\begin{array}{l}\text { - O conhecimento } \\
\text { provém exclusiva- } \\
\text { mente do sujeito. } \\
\text { - Os dons e os } \\
\text { talentos inatos } \\
\text { determinam as } \\
\text { possibilidades de } \\
\text { aprender. } \\
\text { - O conhecimento } \\
\text { depende da } \\
\text { bagagem } \\
\text { hereditária e do } \\
\text { amadurecimento } \\
\text { das estruturas } \\
\text { biológicas. }\end{array}$ & $\begin{array}{l}\text { - O aluno detém o } \\
\text { conhecimento e o } \\
\text { professor não pode } \\
\text { intervir. } \\
\text { - A aprendizagem } \\
\text { surge da } \\
\text { capacidade inata de } \\
\text { conhecer, então a } \\
\text { aula é para } \\
\text { despertar esse } \\
\text { conhecimento } \\
\text { preexistente. } \\
\text { - Aprendem os que } \\
\text { têm vocação e dom } \\
\text { para o campo de } \\
\text { conhecimento. }\end{array}$ & $\begin{array}{l}\text { - Identificação dos } \\
\text { mais aptos e com } \\
\text { talento natural. } \\
\text { - Materiais } \\
\text { atrativos para } \\
\text { despertar o } \\
\text { conhecimento. } \\
\text { - Perspectiva lúdica } \\
\text { e de recreação, a } \\
\text { fim de identificar os } \\
\text { que gostam. } \\
\text { - Parte apenas do } \\
\text { desejo dos alunos. }\end{array}$ \\
\hline
\end{tabular}




\begin{tabular}{|c|c|c|c|}
\hline & $\begin{array}{l}\text { Características } \\
\text { epistemológicas }\end{array}$ & $\begin{array}{c}\text { Características } \\
\text { pedagógicas }\end{array}$ & $\begin{array}{l}\text { Características } \\
\text { das atividades } \\
\text { experimentais }\end{array}$ \\
\hline CONSTRUTIVISMO & $\begin{array}{l}\text { - Os processos de } \\
\text { conhecer situam- } \\
\text { se em uma } \\
\text { interação entre } \\
\text { sujeito e objeto. } \\
\text { - Aprender é } \\
\text { síntese entre os } \\
\text { conhecimentos } \\
\text { prévios e as novas } \\
\text { aquisições. } \\
\text { - A ação é a origem } \\
\text { do conhecimento. }\end{array}$ & $\begin{array}{l}\text { - O professor é um } \\
\text { problematizador } \\
\text { das situações. } \\
\text { - As situações } \\
\text { didáticas mobilizam } \\
\text { experiências ante- } \\
\text { riores e procuram } \\
\text { desafiar os alunos } \\
\text { para irem além. } \\
\text { - Aprendem } \\
\text { aqueles que podem } \\
\text { agir sobre seus } \\
\text { objetos de } \\
\text { conhecimento. }\end{array}$ & $\begin{array}{l}\text { - O experimento } \\
\text { mobiliza saberes } \\
\text { existentes, mas } \\
\text { procura avançar. } \\
\text { - O experimento é } \\
\text { organizado para } \\
\text { proporcionar } \\
\text { feedback. } \\
\text { - Envolve } \\
\text { reelaboração e } \\
\text { construção de } \\
\text { hipóteses e } \\
\text { novidades. }\end{array}$ \\
\hline
\end{tabular}

Fonte: Dados da pesquisa.

A partir desta tabela-resumo e dos dados coletados, pode-se concluir que surgem, sobretudo, atividades práticas sustentadas em modelos empiristas, ainda que abordagens aprioristas apareçam mais ligadas a aspectos motivacionais e de explicação para aqueles que não aprendem (falta de dom ou talento inato). Diferentemente, na concepção construtivista, a experimentação está além do que comumente se pensa (e se faz) em sala de aula. Ela atua como uma forma de promover a ação do sujeito sobre o objeto de conhecimento. Nesta perspectiva epistemológica, é a ação que proporciona o pensamento. Para Borges e Moraes (1998, p. 30), “experimentar, portanto, é submeter à experiência; é pôr à prova; é ensaiar; é conhecer ou avaliar pela experiência." Em outras palavras, experimentar é ter a possibilidade de agir e, a partir desta ação, conhecer o mundo.

Em uma ideia construtivista, para uma atividade poder ser considerada experimentação, ela precisa necessariamente manter a interação entre os dois polos do conhecimento: sujeito e objeto. Se a atividade proposta for apenas uma demonstração de alguma teoria ou fato, corre-se o risco de não provocar nenhuma necessidade de ação cognitiva do sujeito, isto é, não mobilizá-lo a operar mentalmente sobre os desafios que se apresentam. Assim, a demonstração não tem os elementos básicos que compõem uma atividade de experimentação, restringindo-se a uma exibição dos objetos. Se para o professor empirista a atividade experimental pode tornar-se apenas uma atividade de visualização ou de demonstração de uma teoria, na qual ele demonstra o que deve ser feito, possivelmente para o professor construtivista ela é uma ótima oportunidade de problematizar conteúdos e conceitos e fazer pensar. Já o professor sustentado por 
uma epistemologia apriorista pode ver nas experimentações maneiras de despertar os conhecimentos inatos de seus alunos.

Pensando em meios de qualificar a experimentação em sala de aula dos anos iniciais, é possível evidenciar os seguintes pontos:

As conhecidas práticas de aproveitamento de material, justificadas pela economia de recursos, não apresentam maior impacto na atividade experimental, pois os professores não as realizam.

Os roteiros, muitas vezes criticados, constituem recurso importante para os professores dos anos iniciais, devido à ausência de formação para a área de ciências.

0 papel do erro e do imprevisto pode ser abordado nos livros didáticos, haja vista que muitos professores entrevistados o entendem como algo que não deva estar presente em uma atividade de experimentação.

A referência ao cotidiano é ponto de partida, no sentido de atribuir um contexto, sem ainda atingir um nível de significação para o aluno. Livros didáticos que dizem abordar o cotidiano poderiam trazer indicações de problematizar esse cotidiano e de agir sobre ele. Em geral, eles são interpretados como releituras artificiais do dia a dia, com a intenção de atribuir um ar científico a observações corriqueiras.

As práticas de demonstração são voltadas à mobilização de experiências sensoriais, sem maiores incrementos aos processos de pensamento. Restringem-se à pura exibição ou à ação prática sobre os materiais.

Por fim, entendemos que a formação do professor é fator fundamental para o desenvolvimento de metodologias de ensino de ciências nos anos iniciais. Em particular, nesse nível de ensino, os docentes voltam-se mais para a alfabetização, isto é, leitura e escrita, ficando as ciências relegadas a um segundo plano. Nesse sentido, a atividade experimental com os pequenos assume papel bem inferior em relação àquele que deveria ter para garantir uma alfabetização científica e um modo mais contemporâneo de se interpretarem as ciências e a vida.

\section{Referências}

BAGGIO, André. Como alguém pode aprender algo que não conhece? In: DANYLUK, Ocsana Sonia; QUEVEDO, Hercílio Fraga de; MATTOS, Mára Beatriz Pucci de. Conhecimento sem fronteira. v. 4. Passo Fundo: UPF, 2006.

BARDIN, Laurence. Análise de conteúdo. Lisboa: Edições 70, 2002.

BARROS, Aluísio et al. 0 Mestrado do Programa de Pós-graduação em Epidemiologia da UFPel baseado em consórcio de pesquisa: uma experiência inovadora. Rev. bras. epidemiol., São Paulo, v. 11., supl. 1., maio 2008. 
BECKER, Fernando. Modelos Pedagógicos e Modelos Epistemológicos. Educação e Realidade, Porto Alegre, v. 19 (1), 89:96, jan./jun. 1994.

A epistemologia do professor: o cotidiano da escola. 13 ed. Petrópolis: Vozes, 2008.

BOGDAN, Robert; BIKLEN, Sari Knop. Investigação qualitativa em educação. Porto: Porto Editora, 1994. BORGES, Regina Maria Rabello, MORAES, Roque. Educação em Ciências nas Séries Iniciais. Porto Alegre: Sagra Luzzatto, 1998.

Repensando o Ensino de Ciências. In: MORAES, Roque (org.) Construtivismo e ensino de Ciências: reflexões epistemológicas e metodológicas. Porto Alegre: EDIPUCRS, 2008.

BRASIL. Secretaria de Educação Fundamental. Parâmetros Curriculares Nacionais: ciências naturais (1ª a $4^{\mathrm{a}}$ série). Brasília: MEC/SEF, 1997a.

Secretaria de Educação Fundamental. Parâmetros Curriculares Nacionais: meio ambiente, saúde (1 ${ }^{\mathrm{a}}$ a $4^{\mathrm{a}}$ série). Brasília: MEC/SEF, 1997b.

CARVAlHo, Anna Maria Pessoa de et al. Ciências no Ensino Fundamental: o conhecimento físico. São Paulo: Scipione, 1998.

COLL, César. Aprendizagem escolar e construção do conhecimento. Porto Alegre: Artes Médicas, 1994. GIL, Antonio Carlos. Métodos e técnicas de pesquisa social. São Paulo: Atlas, 1999.

GONÇALVES, Fábio Peres; GALIAZZI, Maria do Carmo. A natureza das atividades experimentais no ensino de ciências: um programa de pesquisa educativa nos cursos de Licenciatura. In: MORAES, Roque; MANCUSO, Ronaldo (org). Educação em ciências: Produção de currículos e formação de professores. ljuí: Unijuí, 2004.

HALLAL, Pedro Curi et al. Consórcio de pesquisa: relato de uma experiência metodológica na linha de pesquisa em atividade física, nutrição e saúde do curso de mestrado em Educação Física da UFPel. Revista Brasileira de Atividade Física \& Saúde, Pelotas, v. 14 (3), 156:163, set./dez. 2009.

HARRES, João Batista Siqueira. Natureza da Ciência e implicações para a educação científica. In: MORAES, Roque (org). Construtivismo e ensino de Ciências: reflexões reflexões epistemológicas e metodológicas. Porto Alegre: EDIPUCRS, 2008.

LÜDKE, Menga; ANDRÉ, Marli. Pesquisa em educação: abordagens qualitativas. São Paulo: EPU, 1986. MOLL, Jaqueline; BARBOSA, Maria Carmem Silveira. Construtivismo: desconstituindo mitos e construindo perspectivas. In: BECKER, Fernando; FRANCO, Sérgio Roberto Kieling. (org.). Revisitando Piaget. Porto Alegre: Mediação, 1999.

PIAGET, Jean. A construção do real na criança. 2 ed. Rio de Janeiro: Zahar, 1975.

A Tomada da Consciência. São Paulo: Melhoramentos e EDUSP, 1977.

O nascimento da inteligência na criança. 4 ed. Rio de janeiro: Editora Guanabara S.A., 1987.

ROSITO, Berenice Alvares. 0 ensino de ciências e a experimentação. In: MORAES, Roque (org.). Construtivismo e ensino de Ciências: reflexões epistemológicas e metodológicas. Porto Alegre: EDIPUCRS, 2008.

SILVA, João Alberto. Escola, Complexidade e Construção do Conhecimento. Pelotas: Editora e Gráfica Universitária, 2010. v. 1. 170 p.

Recebido em setembro de 2011.

Aprovado em janeiro de 2012. 
João Alberto da Silva, doutor em Educação pela Universidade Federal do Rio Grande do Sul. Professor Adjunto na Universidade Federal do Rio Grande - FURG, vinculado ao Instituto de Educação e ao Programa de Pós-Graduação em Educação em Ciências. É líder do Núcleo de Estudos em Epistemologia e Educação em Ciências (NUEPEC) e coordena projeto referente ao Observatório Nacional da Educação, financiado pela CAPES e INEP. Publicações recentes: Escola, complexidade e construção do conhecimento (2010); Modelos de Significação e pensamento lógico-matemático (2009). E-mail: joaosilva@furg.br.

Julio Cesar Bresolin Marinho, mestrando do Programa de Pós-Graduação em Educação em Ciências pela Universidade Federal do Rio Grande. Participa do Núcleo de Estudos em Epistemologia e Educação em Ciências (NUEPEC). Publicação recente: Gestão e Avaliação Institucional: múltiplos processos (In: Gionara Tauchen [Org.]. Gestão educacional. Rio Grande: Editora da FURG, 2011, v. 3, p. 109-114). E-mail: marinhojcblagmail.com.

Grasiele Ruiz Silva, mestranda do Programa de Pós-Graduação em Educação em Ciências pela Universidade Federal do Rio Grande. Participa do Núcleo de Estudos em Epistemologia e Educação em Ciências (NUEPEC). Publicação recente: Parâmetros legais e políticos da organização curricular para a educação básica (co-autoria com: MARTINS, Everton. In: Gionara Tauchen [Org.]. Coleção: Cadernos Pedagógicos em EaD. Rio Grande: Universidade Federal do Rio Grande, 20110. E-mail: ruiz.grasidamail.com.

Roberta Chiesa Bartelmebs, mestre em Educação em Ciências pela Universidade Federal do Rio Grande. Professora da Universidade Aberta do Brasil (UAB). Participa do Núcleo em Estudos em Epistemologia e Educação em Ciências (NUEPEC). Publicação recente: Teoria e prática do ensino de astronomia nos anos iniciais: mediação das aprendizagens por meio de perguntas (co-autoria com: BARTELMEBS, Roberta Chiesa; MORAES, Roque. Ensino de Ciências e Tecnologia em Revista [Revista Eletrônica], 2011). E-mail: betachiesadyahoo.com.br. 